\title{
Solvation and Reaction of Ammonia in Molecularly Thin Water Films
}

\author{
Barbara A. J. Lechner, ${ }^{\dagger} \perp$ Youngsoon Kim, ${ }^{\ddagger}, \perp$ Peter J. Feibelman, ${ }^{\S}$ Graeme Henkelman, ${ }^{\|}$Heon Kang, ${ }^{\ddagger}$ \\ and Miquel Salmeron* ${ }^{\dagger} \dagger$ \\ ${ }^{\dagger}$ Materials Sciences Division, Lawrence Berkeley National Laboratory, Berkeley, California 94720, United States \\ ${ }^{\ddagger}$ Department of Chemistry, Seoul National University, Seoul 151-747, Korea \\ ${ }_{1401}$ Sigma Chi Road NE, Albuquerque, New Mexico 87106, United States \\ "Department of Chemistry and the Institute for Computational Engineering and Sciences, The University of Texas at Austin, Austin, \\ Texas 78712-0165, United States
}

ABSTRACT: Determining the interaction and solvation structure of molecules with solvents near a surface is of fundamental importance for understanding electro- and photochemical processes. Here we used scanning tunneling microscopy (STM) to investigate the adsorption and solvation structure of ammonia on water monolayers on $\mathrm{Pt}(111)$. We found that at low coverage $\mathrm{NH}_{3}$ binds preferentially to $\mathrm{H}_{2} \mathrm{O}$ molecules that are slightly elevated from the surface and weakly bound to the metal. Density functional theory (DFT) calculations showed that as the $\mathrm{NH}_{3}$ molecule descends onto the water adlayer a high-lying water molecule reorients with zero energy barrier to expose a dangling $\mathrm{OH}$ ligand to $\mathrm{H}$-bond $\mathrm{NH}_{3}$. We also found that $\mathrm{NH}_{3}$ prefers to bind to the metal substrate when water only partially covers the surface, indicating that $\mathrm{NH}_{3}$ is more strongly attracted to the metal than to $\mathrm{H}_{2} \mathrm{O}$. In addition to this solvation interaction, a proton transfer reaction occurs as revealed by reflection-absorption infrared spectroscopy (RAIRS), leading to the formation of ammonium ions $\left(\mathrm{NH}_{4}^{+}\right)$in addition to molecularly adsorbed $\mathrm{NH}_{3}$.

\section{INTRODUCTION}

Because of the economic importance of corrosion, industrial catalysis, and electrochemistry, the interplay of hydrogen bonding and water-metal interactions has been studied extensively. ${ }^{1-3}$ As a result of such efforts, the first wetting layer on many metals at cryogenic temperatures was found to have no dangling $\mathrm{H}$ bonds $\mathrm{s}^{2,4}$ and thus, potentially, to behave hydrophobically; water monolayers on $\mathrm{Pt}(111)$ are a representative example. ${ }^{5}$ The hydrogen atoms in the first wetting layer either form $\mathrm{H}$-bonds to neighboring molecules or point toward the surface. ${ }^{4,6-8}$ Growth of metastable multilayer water films that preserve an $\mathrm{H}$-down orientation of water has been proposed to occur on $\mathrm{Pt}(111)$, resulting in the formation of "ferroelectric ice". The growth of entropically favorable proton-disordered ice requires rotating some of the molecules in the first layer to expose dangling $\mathrm{H}$ atoms. ${ }^{10,11}$ In addition to energetic effects, kinetic hindrance of such molecular reorientation has been invoked as the reason for the hydrophobic character of water monolayer films. ${ }^{4,12}$ In previous work, the adsorption of $\mathrm{CO}$ and $\mathrm{N}_{2}$ at $20 \mathrm{~K}$ was found to flip some $\mathrm{H}$-down water molecules into an $\mathrm{H}$-up configuration on $\operatorname{Pt}(111),{ }^{13}$ implying that the flipping energy barrier is low.

On the more reactive $\mathrm{Ru}(0001)$ surface, known to dissociate $\mathrm{H}_{2} \mathrm{O}$ at temperatures as low as $138 \mathrm{~K},{ }^{14}$ low-energy sputtering (LES), reactive ion scattering (RIS), and reflection-absorption infrared spectroscopy (RAIRS) showed that the $\mathrm{H}_{2} \mathrm{O}$ monolayer is acidic enough to protonate $\mathrm{NH}_{3}$ to form $\mathrm{NH}_{4}{ }^{+15,16}$ However, owing to the spatially averaging nature of the techniques used in these experiments, no information could be obtained on the structure and spatial distribution of the products formed.

The present study, which is part of an effort to understand solvation phenomena, provides the first real-space images of molecular adsorption on a water monolayer and the initial adsorption sites, which correspond to slightly lifted molecules. Through DFT calculations we discovered that on $\mathrm{Pt}(111)$ the adsorption causes such water molecules to rotate and expose an $\mathrm{H}$ atom to form a hydrogen bond with the incoming $\mathrm{NH}_{3}$. Most notably, such a process proceeds without an energy barrier. Further, we have found that ammonia bonds more strongly to $\mathrm{Pt}$ than to $\mathrm{H}_{2} \mathrm{O}$ and thus segregates from water. This preference of adsorption on the metal is in contrast with the intimately mixed structures on $\mathrm{Cu}(110)$ predicted by DFT calculations, ${ }^{17}$ a behavior that we attribute to attraction between $\mathrm{NH}_{3}$ and the unfilled d-bands of Pt.

\section{METHODS}

Scanning tunneling microscopy (STM) experiments were performed in a home-built low-temperature microscope described elsewhere. ${ }^{18}$ A $\mathrm{Pt}(111)$ single crystal (Princeton Scientific) was mounted in an ultrahigh vacuum (UHV) chamber with a base pressure of $<7 \times 10^{-11}$ mbar and cleaned by argon ion sputtering at $1 \mathrm{kV}$ followed by annealing to $1300 \mathrm{~K}$ and heating in $5 \times 10^{-7}$ mbar oxygen at $1200 \mathrm{~K}$ for 15

Received: August 3, 2015

Revised: September 16, 2015

Published: September 17, 2015 
min to remove carbon contaminations. A final annealing step to $1200 \mathrm{~K}$ in UHV removed residual oxygen from the surface. Auger electron spectroscopy and STM confirmed that the surface had less than $1 \%$ of defects and impurities and consisted of (111) terraces with an average width of $>100 \mathrm{~nm}$. Water (Sigma-Aldrich, deuterium depleted, $<1$ ppm $\mathrm{D}_{2} \mathrm{O}$ ) was purified by freeze, pump, and thaw cycles prior to being dosed onto the cooled sample through a directional dosing tube. The sample temperature and time were adjusted to obtain different water structures. Islands of a $(\sqrt{ } 37 \times \sqrt{ } 37) \mathrm{R} 25.3^{\circ}$ structure and a complete $(\sqrt{ } 39 \times \sqrt{ } 39) \mathrm{R} 16.1^{\circ}$ water film were formed by different exposures at $140 \mathrm{~K}$, while a $(\sqrt{3} \times$ $\sqrt{3}) \mathrm{R} 30^{\circ}$ water layer was formed by depositing $\mathrm{H}_{2} \mathrm{O}$ at $77 \mathrm{~K}$ and annealing the surface to $140 \mathrm{~K}$. A clean $\mathrm{Pt}(111)$ surface was recovered after annealing to $160 \mathrm{~K}$ for $20 \mathrm{~min}$, indicating that the water structures consist of intact $\mathrm{H}_{2} \mathrm{O}$ molecules and do not contain hydroxyl species. ${ }^{19}$ Ammonia (Sigma-Aldrich, 99.99\%) was deposited through another directional dosing tube at sample temperatures of 5 and $77 \mathrm{~K}$. Heating the sample to 350 $\mathrm{K}$ desorbed ammonia to recover the clean $\mathrm{Pt}(111)$ surface.

Reflection-absorption infrared spectroscopy (RAIRS) measurements were performed in a multipurpose UHV surface analysis chamber equipped with instrumentation for LES, RIS, and temperature-programmed desorption (TPD), with a background pressure of $<2 \times 10^{-10} \mathrm{mbar}^{20}$ The experiment was performed in a grazing angle $\left(84^{\circ}\right)$ reflection geometry, with linearly p-polarized infrared (IR) light in a Fourier transform IR instrument (PerkinElmer) equipped with a mercury-cadmium telluride detector. In this arrangement, RAIRS detects vibrations with the transition dipole moment perpendicular to the surface. All RAIR spectra were averaged 256 times at a spectral resolution of $4 \mathrm{~cm}^{-1}$ and measured at a temperature of $90 \mathrm{~K}$. The water layer was prepared by vapor deposition at $140 \mathrm{~K}$, conditions known to produce $(\sqrt{ } 37 \times$ $\sqrt{37) R 25.3^{\circ}}$ and $(\sqrt{39} \times \sqrt{39}) \mathrm{R} 16.1^{\circ}$ water films depending on exposure. ${ }^{2,21}$ The surface coverage of water and ammonia on $\mathrm{Pt}(111)$ was estimated from TPD experiments. ${ }^{22,23}$

We generated DFT results using the projector augmented wave (PAW) version ${ }^{24,25}$ of the VASP, plane-wave DFT code. $^{26,27}$ Electron exchange-correlation effects were treated in the Perdew-Burke-Ernzerhof (PBE) version of the generalized gradient approximation. ${ }^{28}$ We modeled the metal substrate as a three-layer $\mathrm{Pt}(111)$ slab, fixing its lowest layer atoms at theoretical bulk Pt positions (PBE lattice constant $=3.97 \AA$, compared to experiment $=3.92 \AA)$.

A perfect $(\sqrt{ } 37 \times \sqrt{37}) \mathrm{R} 25.3^{\circ} \mathrm{H}_{2} \mathrm{O}$ layer was initially adsorbed on the uppermost $\mathrm{Pt}$ layer and an $\mathrm{NH}_{3}$ molecule situated with its symmetry axis normal to the slab. Its $\mathrm{H}$ atoms were set higher than its $\mathrm{N}$ atom, which was $5.6 \AA$ directly above the $\mathrm{O}$ atom of a high-lying, $\mathrm{H}$-down water molecule. In the final state of the sticking calculation, the $\mathrm{NH}_{3}$ had accepted an $\mathrm{H}$ bond from the underlying host $\mathrm{H}_{2} \mathrm{O}$ molecule, whose free $\mathrm{OH}$ ligand had flipped up to bind the $\mathrm{NH}_{3}$. In the final state, the $\mathrm{N}$ atom was located $2.77 \AA$ away from the $\mathrm{O}$ atom, and the system had gained an adsorption energy of about $0.42 \mathrm{eV}$.

We took pains to cancel unphysical fields associated with adsorption on the upper Pt surface only. ${ }^{29}$ The accuracy of the cancellation requires a sufficiently wide vacuum region $(19.2 \AA)$ between each slab with its upper-layer adsorbates and the bottom of its periodic neighbor slab. Thus, we set the distance between the $\mathrm{NH}_{3}$ molecule and the bottom of the periodic image slab above it to about $13.6 \AA$.
To estimate the $\mathrm{NH}_{3}$ sticking barrier, we used the Climbing Image Nudged Elastic Band Method ${ }^{30}$ (CINEB) with five images spaced along the sticking path (minimum energy path, MEP). Michaelides, Alavi, and King ${ }^{31}$ have found, for an idealized first layer of water on $\mathrm{Ru}(0001)$, that rotation of a water molecule in its $\mathrm{H}-\mathrm{O}-\mathrm{H}$ plane is the low-energy mode for replacing a downward-pointing free $\mathrm{OH}$ by an upwardpointing one. We assumed the same would hold here. This assumption was amply validated by our discovery, discussed further below, that the $\mathrm{OH}$ flip then proceeds with no barrier at all.

We conducted initial calculations using a gamma-point-only surface Brillouin zone (SBZ) sample and a plane-wave cutoff equal to $400 \mathrm{eV}$. We then checked the quality of the results by redoing the calculations with the SBZ sample increased to $3 \times 3$ or the plane-wave cutoff raised to $756 \mathrm{eV}$. Because the changes associated with these improvements were small, we assumed they are additive.

\section{RESULTS AND DISCUSSION}

First Water Layer on $\mathrm{Pt}(111)$. On $\mathrm{Pt}(111)$, water adsorbs intact and forms three ordered monolayer (ML) structures, 5,32 representative images of which are shown in Figure 1 . The energetically most stable structure is a $(\sqrt{ } 37 \times \sqrt{37}) \mathrm{R} 25.3^{\circ}$ arrangement of pentagons, hexagons, and heptagons (henceforth termed R37 structure) exhibiting a Moiré-like pattern as shown in Figure 1a. DFT calculations showed that all molecules in this structure adsorb either flat-lying or with a hydrogen
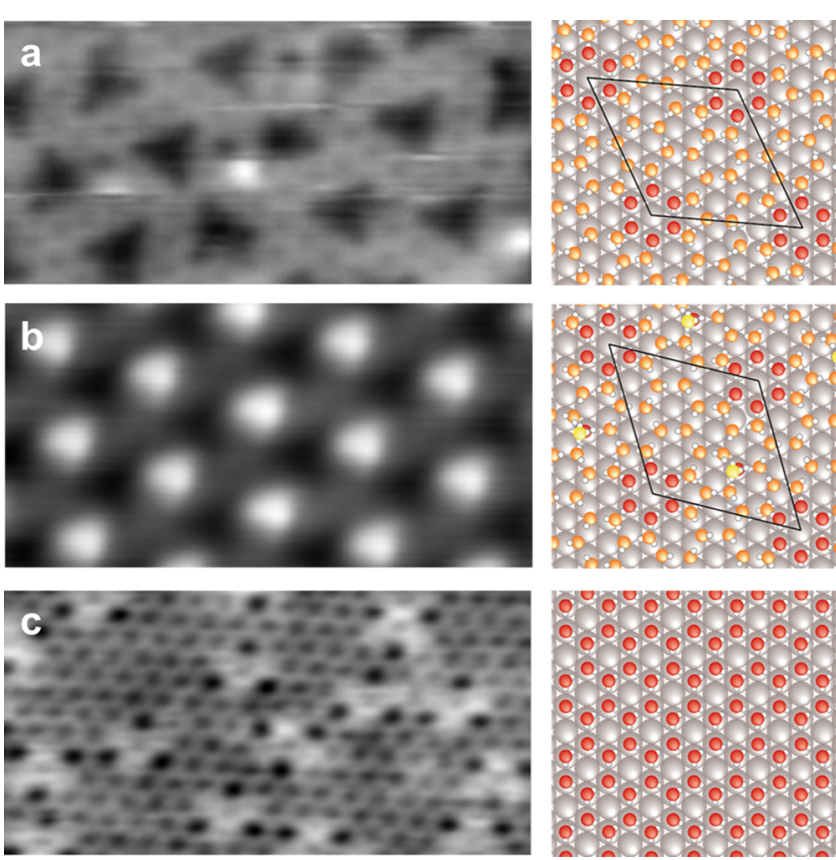

Figure 1. Water exhibits three different monolayer structures on $\mathrm{Pt}(111)$. (a) The $(\sqrt{ } 37 \times \sqrt{ } 37) \mathrm{R} 25.3^{\circ}$ structure is energetically most favorable. (b) The $(\sqrt{39} \times \sqrt{39}) \mathrm{R} 16.1^{\circ}$ structure forms when a full wetting layer is achieved. The bright spots on top of the Moiré structure are due to a single second layer water molecule per unit cell. (c) The $(\sqrt{3} \times \sqrt{3}) \mathrm{R} 30^{\circ}$ structure exhibits some hexagons with a dark center, in our images, which we attribute to $\mathrm{H}$ atom impurities trapped inside and pinning the water layer to the substrate. Image parameters: (a) $U=-150 \mathrm{mV}, I=14 \mathrm{pA}, 10 \mathrm{~nm} \times 5 \mathrm{~nm}, 5 \mathrm{~K}$, (b) $U=$ $200 \mathrm{mV}, I=15 \mathrm{pA}, 10 \mathrm{~nm} \times 5 \mathrm{~nm}, 5 \mathrm{~K},(\mathrm{c}) U=150 \mathrm{mV}, I=10 \mathrm{pA}, 10$ $\mathrm{nm} \times 5 \mathrm{~nm}, 77 \mathrm{~K}$. 
atom pointing toward the substrate. Water molecules bonded close to the surface, through a $\mathrm{Pt}-\mathrm{O}$ bond, appear darker in STM images (tip closer to the surface), while molecules not in registry with the substrate are slightly lifted off the surface and appear brighter in the image (tip farther away from the surface).$^{5}$ As the coverage is increased the surface rearranges to form a $(\sqrt{39} \times \sqrt{ } 39) \mathrm{R} 16.1^{\circ}$ structure $(\mathrm{R} 39$ structure $)$, which is a slightly denser arrangement of pentagons, hexagons, and heptagons. The R39 structure also consists of flat-lying and of $\mathrm{H}$-down-oriented molecules and typically includes one second layer water molecule per unit cell, which exposes a dangling $\mathrm{H}$ atom. The first layer again appears as a Moiré of closely bonded (dark) and lifted (bright) molecules in STM, on top of which additional $\mathrm{H}_{2} \mathrm{O}$ molecules form a regular array of bright spots (cf. Figure 1b).

In addition to these two energetically favored structures, water can form a $(\sqrt{3} \times \sqrt{3}) \mathrm{R} 30^{\circ}$ structure (R3 structure), which is $0.1 \mathrm{eV} /$ molecule less stable than the R37 structure. $^{5}$ Mixed water-hydroxyl films, formed by coadsorption of $\mathrm{H}_{2} \mathrm{O}$ and $\mathrm{O}$ atoms ${ }^{19}$ or by electron injection after prolonged scanning in an STM experiment, ${ }^{32}$ were reported to exhibit $(\sqrt{3} \times \sqrt{3}) \mathrm{R} 30^{\circ}$ geometry. In the present case, however, the clean substrate was recovered after annealing to $160 \mathrm{~K}$, indicating that the $\mathrm{H}_{2} \mathrm{O}$ molecules were intact, ${ }^{19}$ forming an array of hexagons resembling a flattened bilayer of the basal plane of hexagonal $I_{h}$ ice. In our STM images, some of the hexagons in the R3 phase exhibit a dark center (cf. Figure 1c). In previous experiments on $\mathrm{Ru}(0001)$, a similar phenomenon was observed, which could be explained as a result of hydrogen atoms being trapped inside the water hexagon. ${ }^{14}$ Since $\mathrm{H}_{2}$ is a common contaminant in a vacuum chamber, we propose $\mathrm{H}$ atoms trapped in the center of the water hexagon as the stabilizing agent of the R3 structure. In addition, we observe narrow regions separating water hexagons that appear brighter. In analogy with the $\mathrm{R} 37$ and $\mathrm{R} 39 \mathrm{H}_{2} \mathrm{O}$ structures, we assume the brighter regions contain water molecules that are slightly lifted off the surface. To the best of our knowledge, such a buckled structure has not been reported previously.

Adsorption of Ammonia on a Fully Water-Covered Surface. To study the interaction of ammonia with water, we first adsorbed $\mathrm{NH}_{3}$ on a surface fully covered by a water layer, either in the R39 or the R3 structure. Figure 2a shows a highresolution STM image recorded after adsorption of ammonia on the R39 water monolayer, revealing two new species. First, we observe that some of the bright bumps of the second layer water molecules are replaced by even brighter protrusions. The second layer water molecules in this structure were shown to exhibit a dangling $\mathrm{H}$ atom, ${ }^{5,13}$ suggesting that ammonia can $\mathrm{H}$ bond to such a molecule or displace it to form a hydrogen bond with first layer molecules. Second, some of the water hexagons commensurate with the substrate (located in the darker areas) show a new species in their center, imaged as a protrusion inside the dark triangles.

To identify the species observed in STM chemically, we performed RAIRS experiments of ammonia on 1.2 ML water, i.e., on a complete first and partial second layer, shown in panel I of Figure 3. Before ammonia adsorption, the pure water spectrum shows the expected $\mathrm{O}-\mathrm{H}$ stretch $\left(\sim 3390 \mathrm{~cm}^{-1}\right)$ and scissors $\left(\sim 1630 \mathrm{~cm}^{-1}\right)$ modes of water. The appearance of a dangling $\mathrm{OH}$ peak at $3710 \mathrm{~cm}^{-1}$ in the spectrum for pure water is in line with the presence of second layer water molecules in the R39 structure that expose dangling $\mathrm{H}$ atoms. ${ }^{5,13}$ Upon ammonia adsorption (cf. Figure $3 \mathrm{~b}$ ) the intensity of the
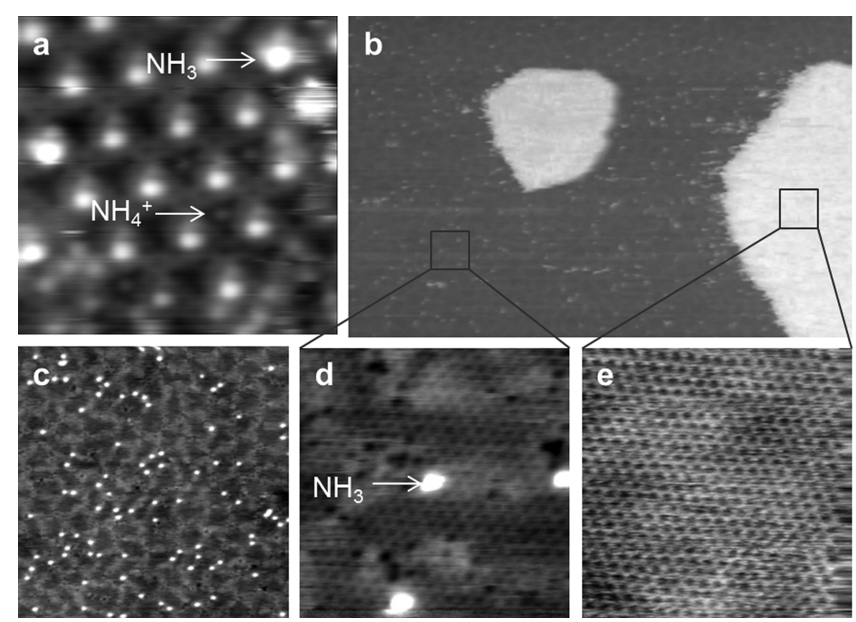

Figure 2. STM images of ammonia adsorption on a completely watercovered $\mathrm{Pt}(111)$ surface. (a) On the $\mathrm{R} 39$ water layer, $\mathrm{NH}_{3}$ adsorbs at the location of the individual second layer water molecules, evident as a change in brightness, while $\mathrm{NH}_{4}^{+}$ions appear in the center of the dark water hexagons. (b) When adsorbed on a full R3 monolayer film (dark gray), with additional islands of a second water layer (light gray), ammonia (bright protrusions) bonds to water molecules in areas in the first monolayer that are lifted off the substrate and thus appear brighter, as evident in close-ups (c) and (d), while it does not adsorb on the flat and ordered second layer islands, shown in (e). Image parameters: (a) $U=200 \mathrm{mV}, I=15 \mathrm{pA}, 10 \mathrm{~nm} \times 10 \mathrm{~nm}, 5 \mathrm{~K}$, (b) $U=$ $200 \mathrm{mV}, I=17 \mathrm{pA}, 143 \mathrm{~nm} \times 93 \mathrm{~nm}, 77 \mathrm{~K},(\mathrm{c}) U=200 \mathrm{mV}, I=17$ $\mathrm{pA}, 50 \mathrm{~nm} \times 50 \mathrm{~nm}, 77 \mathrm{~K}$, (d) $U=200 \mathrm{mV}, I=17 \mathrm{pA}, 10 \mathrm{~nm} \times 10$ $\mathrm{nm}, 77 \mathrm{~K},(\mathrm{e}) U=240 \mathrm{mV}, I=23 \mathrm{pA}, 10 \mathrm{~nm} \times 10 \mathrm{~nm}, 77 \mathrm{~K}$.

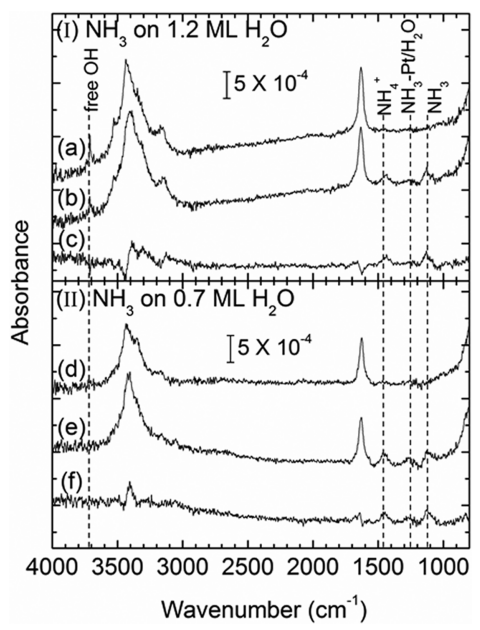

Figure 3. RAIRS investigation of $\mathrm{NH}_{3}$ adsorption on a water film on $\mathrm{Pt}(111)$. Panel I shows results for a full water layer with a partial second layer coverage (1.2 ML), while panel II presents the case of an incomplete water layer of $0.7 \mathrm{ML}$ coverage. (a) and (d) show spectra of the pure $\mathrm{H}_{2} \mathrm{O}$ films prepared at $140 \mathrm{~K}$. Spectra (b) and (e) were measured after deposition of $\mathrm{NH}_{3}$ onto the respective water layers, while (c) and (f) display the absorbance difference before and after ammonia adsorption. The dashed lines mark the vibrational bands of dangling $\mathrm{OH}$ groups, ammonium $\left(\mathrm{NH}_{4}^{+}\right)$, and ammonia $\left(\mathrm{NH}_{3}\right)$.

dangling $\mathrm{OH}$ band decreases, also in line with the STM observation that ammonia bonds to the dangling $\mathrm{H}$ of the second layer water molecules to form an $\mathrm{O}-\mathrm{H} \cdots \mathrm{N}$ bond. At the same time, two strong bands at $\sim 1110$ and $\sim 1470 \mathrm{~cm}^{-1}$ and a weaker one at $\sim 1250 \mathrm{~cm}^{-1}$ appear, which can be assigned to the $\nu_{2}$ (umbrella) mode of $\mathrm{NH}_{3}$ adsorbed on water, ${ }^{33}$ the $\nu_{4}$ 
(asymmetric deformation) mode of ammonium $\left(\mathrm{NH}_{4}^{+}\right),{ }^{15,16,33-36}$ and the $\nu_{2}$ mode of $\mathrm{NH}_{3}$ bonded to both $\mathrm{Pt}$ and $\mathrm{H}_{2} \mathrm{O}$, e.g., at the edges of holes in the $\mathrm{ML},{ }^{35,37}$ respectively. RAIRS experiments thus indicate that ammonia can adsorb onto the water ML, bonding to the dangling $\mathrm{H}$ atom of second layer $\mathrm{H}_{2} \mathrm{O}$ and also to the $\mathrm{Pt}$ substrate, where available. Further, the formation of $\mathrm{NH}_{4}{ }^{+}$by proton transfer from water to ammonia is observed, which does not readily occur in the liquid state, in accordance with the findings on a water $\mathrm{ML}$ on $\mathrm{Ru}(0001) .{ }^{20,22}$ We propose that the protrusions in the center of the commensurate water hexagons in our STM images correspond to ammonium ions, while the bright bumps on the second layer water molecules are ammonia molecules hydrogen bonded to the dangling $\mathrm{OH}$ groups. This assignment is consistent with the observation that $\mathrm{NH}_{4}{ }^{+}$is attracted to its image charge in the substrate and therefore likely displaces to bond as closely to the surface as possible, i.e., in the lowest water regions.

In comparison, Figure $2 \mathrm{~b}$ shows STM images of a surface with a complete first layer of the energetically less favorable R3 water structure (gray) plus second layer islands (brighter areas). High-resolution images of the monolayer $\mathrm{R} 3$ regions reveal the presence of ammonia molecules, imaged as bright spots in Figures $2 \mathrm{c}$ and d. However, on the second layer water islands, also with R3 structure, no ammonia molecules were found (cf. Figure 2e). An interesting observation is that ammonia only adsorbs in regions of the first layer where the R3 structures appears brighter in STM. The preference of ammonia to bond to lifted water suggests that these water molecules either expose a dangling $\mathrm{H}$ atom or can be easily flipped around to expose one.

Adsorption of Ammonia on a Partially Water-Covered Surface. Having studied the adsorption of ammonia on a full water layer, we coadsorbed ammonia with a partial water monolayer to investigate the effect of the $\mathrm{Pt}(111)$ substrate. Figure $4 \mathrm{a}$ shows a representative STM image obtained after dosing ammonia onto a submonolayer water film in the R3 phase. We observe substantial segregation of the two species, with water-forming monolayer islands (imaged as bright regions) and ammonia molecules adsorbed preferentially on areas of bare Pt (bright protrusions on the dark background). Two different species can be distinguished in the bare substrate regions, appearing as protrusions of different height (brightness), which correspond to $\mathrm{NH}_{3}$ monomers and dimers, as previously observed on $\mathrm{Ru}(0001){ }^{38}$ As on $\mathrm{Ru}$, the dimers could be dissociated into monomers by applying a $2 \mathrm{~V}$ pulse with the tip. On the R3 water islands (cf. Figure 4c), very few bright protrusions are observed, suggesting that ammonia moves off the water islands and onto the substrate.

We can understand the formation of separate $\mathrm{H}_{2} \mathrm{O}$ and $\mathrm{NH}_{3}$ domains by considering bond strengths. The interaction of $\mathrm{NH}_{3}$ and $\mathrm{H}_{2} \mathrm{O}$ is based on hydrogen bonding, while the molecule-substrate interaction is covalent. In the bulk, the molecules can reorient easily to optimize the $\mathrm{H}$-bond network, forming intimately mixed crystal structures. ${ }^{39}$ On a metal surface, however, the molecules cannot reorient freely, and adsorption structures are thus determined by the interplay of adsorbate-substrate and interadsorbate bond strengths. For $\mathrm{H}_{2} \mathrm{O} / \mathrm{Pt}(111)$, the interactions are of similar strength, whereas for $\mathrm{NH}_{3} / \mathrm{Pt}(111)$, the adsorbate-substrate interaction dominates. ${ }^{4,40}$ Thus, water grows in crystalline films on $\mathrm{Pt}(111)$, while ammonia forms irregular assemblies of molecules bonded to Pt through the $\mathrm{N}$ atom. ${ }^{40-42}$ The hydrogen bond strength in

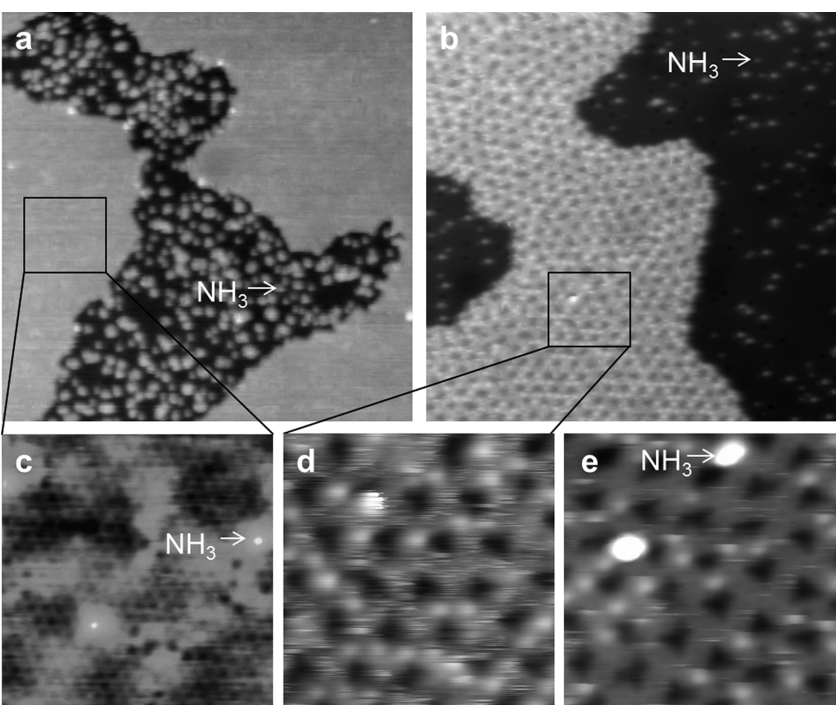

Figure 4. Water and ammonia coadsorption on $\mathrm{Pt}(111)$. (a) When coadsorbed with R3 water islands (gray) at $77 \mathrm{~K}$, ammonia adsorbs predominantly on bare Pt (bright protrusions on black background), and only few molecules are found on top of water (c). (b) On R37 islands at $5 \mathrm{~K}$, ammonia can bond both to $\mathrm{Pt}$ and water, but the molecules move under the STM tip, as evident by the streaks in (d). After prolonged scanning, most of the mobile species have moved onto the Pt substrate, and only a low coverage of ammonia remains on water (e). Image parameters: (a) $U=150 \mathrm{mV}, I=12 \mathrm{pA}, 50 \mathrm{~nm} \times 50$ $\mathrm{nm}, 77 \mathrm{~K},(\mathrm{~b}) U=-210 \mathrm{mV}, I=8 \mathrm{pA}, 50 \mathrm{~nm} \times 50 \mathrm{~nm}, 5 \mathrm{~K},(\mathrm{c}) U=$ $150 \mathrm{mV}, I=12 \mathrm{pA}, 10 \mathrm{~nm} \times 10 \mathrm{~nm}, 77 \mathrm{~K}$, (d) $U=-150 \mathrm{mV}, I=12$ $\mathrm{pA}, 10 \mathrm{~nm} \times 10 \mathrm{~nm}, 5 \mathrm{~K}$, (e) $U=-150 \mathrm{mV}, I=12 \mathrm{pA}, 10 \mathrm{~nm} \times 10$ $\mathrm{nm}, 5 \mathrm{~K}$.

water is typically $26 \mathrm{~kJ} / \mathrm{mol}$, while for bulk $\mathrm{NH}_{3}$ it is only $\sim 11$ $\mathrm{kJ} / \mathrm{mol}^{43}$ Moreover, amounting to $23 \mathrm{~kJ} / \mathrm{mol}$, the $\mathrm{O}-\mathrm{H} \cdots \mathrm{N}$ bond is stronger than both the $\mathrm{N}-\mathrm{H} \cdots \mathrm{N}$ and $\mathrm{N}-\mathrm{H} \cdots \mathrm{O}(11 \mathrm{~kJ} /$ mol) bonds, ${ }^{43}$ implying that it is preferable for $\mathrm{NH}_{3}$ to bond to $\mathrm{H}-\mathrm{O}$ through the $\mathrm{N}$ atom.

To investigate the interaction of ammonia with a water layer known to expose no dangling $\mathrm{H}$ atoms, we deposited $\mathrm{NH}_{3}$ onto R37 water islands at $5 \mathrm{~K}$ (cf. Figure $4 \mathrm{~b}$ ). Such low-temperature experiments not only limit adsorbate mobility but also provide important information about the energy barrier involved in the $\mathrm{NH}_{3}$ adsorption process. As $k_{\mathrm{B}} \mathrm{T}$ is only $0.4 \mathrm{meV}$ at $5 \mathrm{~K}$, where $k_{\mathrm{B}}$ is the Boltzmann constant, observing a rotation from $\mathrm{H}$ down to H-up water similar to that proposed on R3 water suggests a very low activation barrier. Figure $4 \mathrm{~d}$ shows a highresolution image recorded shortly after ammonia deposition. The Moire structure of the R37 water structure is still clearly visible, but the lifted regions are covered in streaks and bright spots, confirming that $\mathrm{NH}_{3}$ adsorption occurs even at $5 \mathrm{~K}$. The streaky appearance suggests that molecules are moving under the tip. Since the streaks only appear on top of brightly imaged water regions, we infer that the mobile species bond to $\mathrm{H}_{2} \mathrm{O}$ molecules that are weakly bonded to the substrate, analogous to our observation on the R3 water film. After prolonged scanning, the mobile species largely disappear, and the structure of the underlying water layer becomes visible, as in Figure 4e. These observations indicate that some molecules move off the water layer and onto the Pt substrate where they can bind more strongly, likely through the interaction with the STM tip. In addition, we observe occasional bright bumps, one of the same height as the streaks, and also a brighter kind, suggesting that two species are present. 
To determine whether the protrusions observed in STM are due to ammonia or ammonium species, we conducted RAIRS measurements of a partially water-covered $\mathrm{Pt}(111)$ surface $(0.7$ ML) before and after $\mathrm{NH}_{3}$ adsorption, shown in panel II of Figure 3. The growth conditions employed here (cf. Methods) imply the presence of an R37 water layer. The conspicuous absence of a free $\mathrm{O}-\mathrm{H}$ stretch band at $\sim 3710 \mathrm{~cm}^{-1}$, characteristic of dangling $\mathrm{OH}$ groups, indicates that the clean R37 water layer exposes no unsaturated $\mathrm{H}$ atoms. ${ }^{4}$ Adsorption of ammonia onto this surface results in vibrational features for $\mathrm{NH}_{3}$ on $\mathrm{H}_{2} \mathrm{O}$ at $1110 \mathrm{~cm}^{-1}, \mathrm{NH}_{3}$ at the $\mathrm{Pt}-\mathrm{H}_{2} \mathrm{O}$ interface at $1250 \mathrm{~cm}^{-1}$, and $\mathrm{NH}_{4}^{+}$at $1470 \mathrm{~cm}^{-1}$. RAIRS thus suggests that, in addition to $\mathrm{H}$-bonding $\mathrm{NH}_{3}$, the water provides protons to form ammonium ions. As the $\mathrm{N}-\mathrm{H} \cdots \mathrm{O}$ bond is weaker than the $\mathrm{O}-\mathrm{H} \cdots \mathrm{N}$ bond, $\mathrm{NH}_{4}{ }^{+}$is likely the more mobile species on $\mathrm{H}_{2} \mathrm{O}$ than $\mathrm{NH}_{3}$ and can thus move off the $\mathrm{H}_{2} \mathrm{O}$ islands onto bare $\mathrm{Pt}$ under the STM tip, where it can decompose into $\mathrm{NH}_{3}$ and $\mathrm{H}^{16}$

Atomic-Scale Details of the $\mathrm{NH}_{3}$ Adsorption Process. Our STM measurements show that $\mathrm{NH}_{3}$ only bonds to regions in an R3 and R37 water film where $\mathrm{H}_{2} \mathrm{O}$ molecules are lifted off the surface and thus weakly bonded to the metal, suggesting that an $\mathrm{H}_{2} \mathrm{O}$ reorients to accommodate the $\mathrm{NH}_{3}$ adsorbate. Since $\mathrm{NH}_{3}$ bonds to the second layer water molecules that expose a dangling $\mathrm{H}$ in the $\mathrm{R} 39$ structure, it is likely that a weakly bonded $\mathrm{H}_{2} \mathrm{O}$ in the $\mathrm{R} 3$ or $\mathrm{R} 37$ film can rotate to provide an $\mathrm{H}$ pointing to the $\mathrm{NH}_{3}$ and forming an $\mathrm{H}$ bond. As this effect is observed even at $5 \mathrm{~K}$, the energy barrier for the process must be low. To investigate the adsorption process and the energetics involved, we performed density functional theory (DFT) calculations, using the climbing image nudged elastic band method. Previous such calculations for a hypothetical, pure $\mathrm{H}_{2} \mathrm{O}$ R3 structure showed barriers for water flipping, of $0.1 \mathrm{eV}$ on $\mathrm{Pt}(111)^{44}$ and $0.3 \mathrm{eV}$ on $\mathrm{Ru}(0001) .{ }^{31}$ Compared to thermal energies of $k_{\mathrm{B}} T=6.6 \mathrm{meV}$ at $77 \mathrm{~K}$ and $0.4 \mathrm{meV}$ at $5 \mathrm{~K}$, these values are too high to explain how $\mathrm{NH}_{3}$ sticking can occur.

Here, we calculated the sticking barrier for the R37 structure, but unlike in the barrier estimates of refs 44 and 31, the molecule descending onto the water layer was present in our calculations. With the $\mathrm{NH}_{3}$ molecule included, rotation of an $\mathrm{H}_{2} \mathrm{O}$ in its $\mathrm{H}-\mathrm{O}-\mathrm{H}$ plane does not begin simply by breaking an $\mathrm{H}$-bond in the water layer. Instead, a new $\mathrm{H}$-bond is forming between the incoming $\mathrm{NH}_{3}$ and the $\mathrm{OH}$ ligand rotating out of the water layer. This is what makes the barrier small: new bonds form as old ones break. High barriers occur in the absence of an adsorbing molecule because the energy of breaking the H-bond is not compensated by new bond formation. The results of our CINEB optimization of the minimum energy trajectory are shown in Figure 5. Note that there is no adsorption barrier, a result we found to be robust against improving the SBZ sample from $1 \times 1$ to $3 \times 3$ or increasing the plane-wave basis cutoff from 400 to $756 \mathrm{eV}$.

\section{CONCLUSIONS}

In conclusion, our investigation of the interaction of two different $\mathrm{H}$-bonding molecules, $\mathrm{NH}_{3}$ and $\mathrm{H}_{2} \mathrm{O}$, on a $\mathrm{Pt}$ substrate provides important information on the molecular level details of the solvation and reaction process of ammonia by water. We found that the ammonia adsorption process involves the rotation of an $\mathrm{H}$-down molecule into an $\mathrm{H}$-up configuration and proceeds without an energy barrier. The solvation structure in that case consists of a single water
MEP for $\mathrm{H}_{2} \mathrm{O}$ flipping in the $\mathrm{H}-\mathrm{O}-\mathrm{H}$ plane

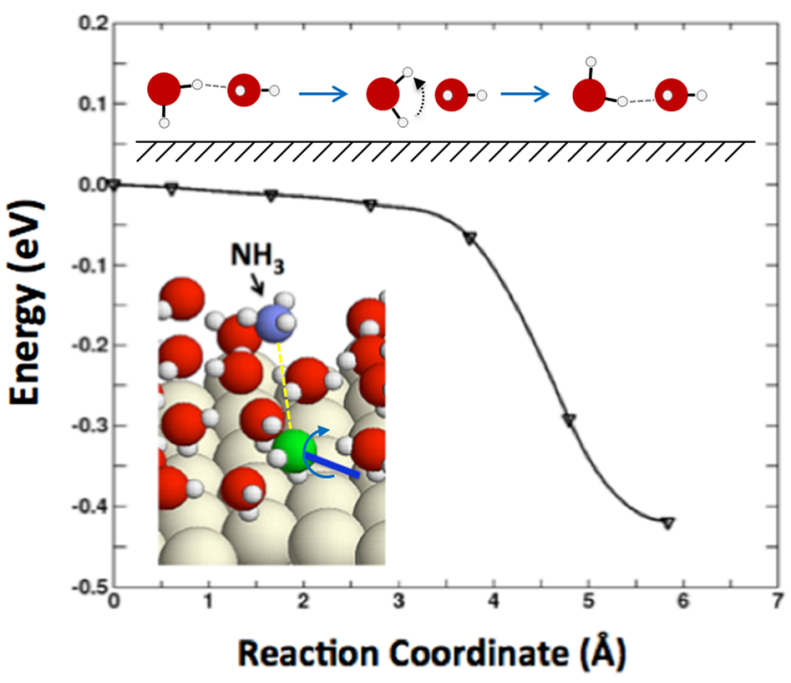

Figure 5. Energetics along the computed minimum energy path for $\mathrm{NH}_{3}$ sticking to a $(\sqrt{37} \times \sqrt{37}) \mathrm{R} 25.3^{\circ} \mathrm{H}_{2} \mathrm{O}$ layer on $\mathrm{Pt}(111)$, computed assuming rotation of the host $\mathrm{H}_{2} \mathrm{O}$ in the $\mathrm{H}-\mathrm{O}-\mathrm{H}$ plane. These results were computed with plane-wave cutoff $=400 \mathrm{eV}$ and a gamma-point SBZ sample. Inset: Initial state of the calculation. The $\mathrm{N}$ atom of the $\mathrm{NH}_{3}$ is colored purple, and the $\mathrm{O}$ of the $\mathrm{H}_{2} \mathrm{O}$ to which it sticks is green. Remaining $\mathrm{O}$ atoms are red, $\mathrm{H}$ atoms white, and $\mathrm{Pt}$ atoms light yellow. The rotation axis of the host $\mathrm{H}_{2} \mathrm{O}$ is indicated by a blue line. The rotation occurs as the $\mathrm{NH}_{3}$ molecule descends and binds.

molecule donating an $\mathrm{H}$ bond to the ammonia molecule $\left(\mathrm{HOH} \cdots \mathrm{NH}_{3}\right)$. This distorts the local environment of the "solvating" molecule, which now does not point its $\mathrm{H}$ to the $\mathrm{Pt}$ surface atoms. On a partially water-covered surface, ammonia prefers to bond to the $\mathrm{Pt}$ substrate rather than to water, resulting in the formation of largely separate water and ammonia domains on the $\mathrm{Pt}(111)$ substrate. We also learned from RAIRS that in addition to solvated $\mathrm{NH}_{3}, \mathrm{NH}_{4}{ }^{+}$ions are formed as a result of proton transfer from $\mathrm{H}_{2} \mathrm{O}$ to $\mathrm{NH}_{3}$. Our experiments show that ammonia flags the molecular sites where water molecules can rotate to expose dangling $\mathrm{H}$ bonds and which are necessary to initiate bulk ice growth.

\section{AUTHOR INFORMATION}

\section{Corresponding Author}

*E-mail: mbsalmeron@lbl.gov.

\section{Author Contributions}

${ }^{\perp}$ These authors contributed equally.

Notes

The authors declare no competing financial interest.

\section{ACKNOWLEDGMENTS}

This work was supported by the Office of Basic Energy Sciences, Division of Materials Sciences and Engineering of the U.S. DOE, under Contract No. DE-AC02-05CH11231. VASP was originally developed at the Institut für Theoretische Physik of the Technische Universität Wien and is under continuing development in the Physics Department of the Universität Wien, Austria. This research used resources of the National Energy Research Scientific Computing Center, which is supported by the Office of Science of the U.S. Department of Energy under Contract DE-AC02-05CH11231. Y. Kim and H. 
Kang acknowledge support by the grant of the National Research Foundation (NRF) of Korea funded by the Korea government (MSIP) (No. 2007-0056095).

\section{REFERENCES}

(1) Henderson, M. A. The Interaction of Water with Solid Surfaces: Fundamental Aspects Revisited. Surf. Sci. Rep. 2002, 46, 1-308.

(2) Hodgson, A.; Haq, S. Water Adsorption and the Wetting of Metal Surfaces. Surf. Sci. Rep. 2009, 64 (9), 381-451.

(3) Carrasco, J.; Hodgson, A.; Michaelides, A. A Molecular Perspective of Water at Metal Interfaces. Nat. Mater. 2012, 11 (8), 667-674.

(4) Kimmel, G. A.; Petrik, N. G.; Dohnálek, Z.; Kay, B. D. Crystalline Ice Growth on $\mathrm{Pt}(111)$ and $\operatorname{Pd}(111)$ : Nonwetting Growth on a Hydrophobic Water Monolayer. J. Chem. Phys. 2007, 126, 114702.

(5) Nie, S.; Feibelman, P. J.; Bartelt, N. C.; Thürmer, K. Pentagons and Heptagons in the First Water Layer on Pt(111). Phys. Rev. Lett. 2010, 105 (2), 026102.

(6) Haq, S.; Hodgson, A. Multilayer Growth and Wetting of $\mathrm{Ru}(0001)$. J. Phys. Chem. C 2007, 111, 5946-5953.

(7) Park, S.; Sposito, G. Structure of Water Adsorbed on a Mica Surface. Phys. Rev. Lett. 2002, 89 (8), 085501.

(8) Miranda, P. B.; Xu, L.; Shen, Y. R.; Salmeron, M. Icelike Water Monolayer Adsorbed on Mica at Room Temperature. Phys. Rev. Lett. 1998, 81 (26), 5876-5879.

(9) Su, X.; Lianos, L.; Shen, Y. R.; Somorjai, G. A. Phys. Rev. Lett. 1998, 80 (7), 1533-1536.

(10) Thürmer, K.; Bartelt, N. Nucleation-Limited Dewetting of Ice Films on Pt(111). Phys. Rev. Lett. 2008, 100 (18), 186101.

(11) Limmer, D. T.; Willard, A. P.; Madden, P.; Chandler, D. Hydration of Metal Surfaces Can Be Dynamically Heterogeneous and Hydrophobic. Proc. Natl. Acad. Sci. U. S. A. 2013, 110 (11), 4200.

(12) Kimmel, G. A.; Petrik, N. G.; Dohnálek, Z.; Kay, B. D. Layer-byLayer Growth of Thin Amorphous Solid Water Films on Pt(111) and Pd(111). J. Chem. Phys. 2006, 125, 044713.

(13) Kimmel, G. A.; Zubkov, T.; Smith, R. S.; Petrik, N. G.; Kay, B. D. Turning Things Downside up: Adsorbate Induced Water Flipping on $\operatorname{Pt}(111)$. J. Chem. Phys. 2014, 141, $18 \mathrm{C} 515$.

(14) Maier, S.; Stass, I.; Cerdá, J. I.; Salmeron, M. Unveiling the Mechanism of Water Partial Dissociation on $\mathrm{Ru}(0001)$. Phys. Rev. Lett. 2014, 112, 126101.

(15) Kim, Y.; Moon, E.; Shin, S.; Kang, H. Acidic Water Monolayer on Ruthenium(0001). Angew. Chem., Int. Ed. 2012, 51, 12806-12809.

(16) Kim, Y.; Shin, S.; Moon, E.; Kang, H. Spectroscopic Monitoring of the Acidity of Water Films on $\mathrm{Ru}(0001)$ : Orientation-Specific Acidity of Adsorbed Water. Chem. - Eur. J. 2014, 20, 3376-3383.

(17) Jones, G.; Jenkins, S. J. Water and Ammonia on $\mathrm{Cu}\{110\}$ : Comparative Structure and Bonding. Phys. Chem. Chem. Phys. 2013, 15 (13), 4785-4798.

(18) Shimizu, T. K.; Mugarza, A.; Cerdá, J. I.; Heyde, M.; Qi, Y.; Schwarz, U. D.; Ogletree, D. F.; Salmeron, M. Surface Species Formed by the Adsorption and Dissociation of Water Molecules on a $\mathrm{Ru}(0001)$ Surface Containing a Small Coverage of Carbon Atoms Studied by Scanning Tunneling Microscopy. J. Phys. Chem. C 2008, 112 (0001), 7445-7454.

(19) Clay, C.; Haq, S.; Hodgson, A. Hydrogen Bonding in Mixed OH + H2O Overlayers on Pt(111). Phys. Rev. Lett. 2004, 92 (4), 046102.

(20) Kang, H. Reactive Ion Scattering of Low Energy Cs+ from Surfaces. A Technique for Surface Molecular Analysis. Bull. Korean Chem. Soc. 2011, 32 (2), 389-398.

(21) Feibelman, P. J.; Kimmel, G. A.; Smith, R. S.; Petrik, N. G.; Zubkov, T.; Kay, B. D. A Unique Vibrational Signature of Rotated Water Monolayers on $\mathrm{Pt}(111)$ : Predicted and Observed. J. Chem. Phys. 2011, 134 (20), 204702.

(22) Zimbitas, G.; Haq, S.; Hodgson, A. The Structure and Crystallization of Thin Water Films on $\mathrm{Pt}(111)$. J. Chem. Phys. 2005, 123 (17), 174701.
(23) Gland, J. L.; Kollin, E. B. Ammonia Adsorption on the Pt(111) and $\mathrm{Pt}(\mathrm{S})-6(111) \mathrm{x}(111)$ Surfaces. Surf. Sci. 1981, 104, 478-490.

(24) Blöchl, P. E. Projector Augmented-Wave Method. Phys. Rev. B: Condens. Matter Mater. Phys. 1994, 50 (24), 17953-17979.

(25) Kresse, G.; Joubert, D. From Ultrasoft Pseudopotentials to the Projector Augmented-Wave Method. Phys. Rev. B: Condens. Matter Mater. Phys. 1999, 59 (3), 1758-1775.

(26) Kresse, G.; Furthmüller, J. Efficient Iterative Schemes for $\mathrm{Ab}$ Initio Total-Energy Calculations Using a Plane-Wave Basis Set. Phys. Rev. B: Condens. Matter Mater. Phys. 1996, 54 (16), 11169-11186.

(27) Kresse, G.; Hafner, J. Ab Initio Molecular-Dynamics Simulation of the Liquid-Metal - Amorphous-Semiconductor Transition in Germanium. Phys. Rev. B: Condens. Matter Mater. Phys. 1994, 49 (20), 14251-14269.

(28) Perdew, J. P.; Burke, K.; Ernzerhof, M. Generalized Gradient Approximation Made Simple. Phys. Rev. Lett. 1996, 77 (18), 38653868.

(29) Neugebauer, J.; Scheffler, M. Adsorbate-Substrate and Adsorbate-Adsorbate Interactions of $\mathrm{Na}$ and $\mathrm{K}$ Adlayers on $\mathrm{Al}(111)$. Phys. Rev. B: Condens. Matter Mater. Phys. 1992, 46, 16067. As corrected by Bengtsson, L. Dipole correction for surface supercell calculations. Phys. Rev. B: Condens. Matter Mater. Phys. 1999, 59, 12301.

(30) Henkelman, G.; Uberuaga, B. P.; Jónsson, H. Climbing Image Nudged Elastic Band Method for Finding Saddle Points and Minimum Energy Paths. J. Chem. Phys. 2000, 113 (22), 9901-9904.

(31) Michaelides, A.; Alavi, A.; King, D. A. Different Surface Chemistries of Water on $\mathrm{Ru}\{0001\}$ : From Monomer Adsorption to Partially Dissociated Bilayers. J. Am. Chem. Soc. 2003, 125, 2746-2755.

(32) Standop, S.; Morgenstern, M.; Michely, T.; Busse, C. H2O on $\mathrm{Pt}(111)$ : Structure and Stability of the First Wetting Layer. J. Phys.: Condens. Matter 2012, 24 (12), 124103.

(33) Pursell, C. J.; Zaidi, M.; Thompson, A.; Fraser-Gaston, C.; Vela, E. Acid - Base Chemistry on Crystalline Ice: $\mathrm{HCl}+\mathrm{NH} 3$. J. Phys. Chem. A 2000, 104 (3), 552-556.

(34) Schutte, W. A.; Khanna, R. K. Origin of the 6.85 Micron Band near Young Stellar Objects: The Ammonium Ion (NH4+) Revisited. Astron. Astrophys. 2002, 398, 1049-1062.

(35) Takaoka, T.; Inamura, M.; Yanagimachi, S.; Kusunoki, I.; Komeda, T. Ammonia Adsorption on Diffusion into Thin Ice Films Grown on Pt(111). J. Chem. Phys. 2004, 121 (9), 4331-4338.

(36) Moon, E. S.; Kim, Y.; Shin, S.; Kang, H. Asymmetric Transport Efficiencies of Positive and Negative Ion Defects in Amorphous Ice. Phys. Rev. Lett. 2012, 108, 1-5.

(37) Ogasawara, H.; Horimoto, N.; Kawai, M. Ammonia Adsorption by Hydrogen Bond on Ice and Its Solvation Ammonia Adsorption by Hydrogen Bond on Ice and Its Solvation. J. Chem. Phys. 2000, 112, $8229-8232$

(38) Maier, S.; Stass, I.; Cerdá, J. I.; Salmeron, M. Bonding of Ammonia and Its Dehydrogenated Fragments on $\mathrm{Ru}(0001)$. J. Phys. Chem. C 2012, 116 (48), 25395-25400.

(39) Olovsson, I.; Templeton, D. H. The Crystal Structure of Ammonia Monohydrate*. Acta Crystallogr. 1959, 12, 827.

(40) Sexton, B. A.; Mitchell, G. E. Vibrational Spectra of Ammonia Chemisorbed on Platinum(111) I. Identification of Chemisorbed States. Surf. Sci. 1980, 99, 523-538.

(41) Peronio, A.; Cepellotti, A.; Marchini, S.; Abdurakhmanova, N.; Dri, C.; Africh, C.; Esch, F.; Peressi, M.; Comelli, G. NH3-NO Coadsorption System on $\mathrm{Pt}(111)$. I. Structure of the Mixed Layer. J. Phys. Chem. C 2013, 117, 21186-21195.

(42) Cepellotti, A.; Peronio, A.; Marchini, S.; Abdurakhmanova, N.; Dri, C.; Africh, C.; Esch, F.; Comelli, G.; Peressi, M. NH3-NO Coadsorption System on $\mathrm{Pt}(111)$. II. Intermolecular Interaction. J. Phys. Chem. C 2013, 117, 21196-21202.

(43) Uras, N.; Buch, V.; Devlin, J. Hydrogen Bond Surface Chemistry: Interaction of $\mathrm{NH} 3$ with an Ice Particle. J. Phys. Chem. B 2000, 104, 9203-9209. 
(44) Meng, S.; Wang, E.; Gao, S. Water Adsorption on Metal Surfaces: A General Picture from Density Functional Theory Studies. Phys. Rev. B: Condens. Matter Mater. Phys. 2004, 69 (19), 195404. 